\title{
Research Status and Trend of Interorganizational Information Systems Based on Knowledge Visualization
}

\author{
Jiao WANG ${ }^{1, a,{ }^{*},}$, Lin SUN ${ }^{2, b}$, Xin ZHANG $^{3, c}$ \\ ${ }^{1}$ School of Information Science and Technology, Northeast Normal University, Chang Chun, China \\ ${ }^{2}$ Department of Business Management, Dalian Neusoft Institute of Information, Dalian, China \\ ${ }^{3}$ School of Management, Jilin University, Changchun, China \\ awangj097@nenu.edu.cn, bunlin@neusoft.edu.cn, ctitanzx@163.com
}

Key words: Interorganizational information systems, Knowledge visualization, Bibliometrics, Research trend.

\begin{abstract}
This paper summarizes the related results of the Interorganizational Information Systems in the journals from the web of Science (WOS) and the Chinese knowledge network (CNKI) to find the research status of interorganizationl information systems. With the help of database management and knowledge visualization methods and tools, we make a visual analysis of the document situation at home and abroad, the co-occurrence of key words, the high frequency authors and co- operation of authors to find the research regularity and research trend of inter-organization information systems. We believe that there are four trends in the field of research, namely, trust factors, Interorganizational Information Systems in cloud computing, configuration analysis methods and social perspectives. And it presents a situation with the core of the factors study.
\end{abstract}

The organizational relationships become more and more complex and wider between organizations. These relationships range from simple supply and demand of goods to cooperative research and business process outsourcing and so on. Faced with worldwide industrial restructuring and a highly complex global competition, an organization can only get the full resources it needs with the help of its partners to meet the diverse needs of its clients. As a result, the dependence among organizations is getting higher and higher, and the cooperation strategy is even more important to the organization. With the change of the competitive form, the information system began to cross the boundary of the organization with the support of information technology and transformed from simple and closed information system within the organization into a complex and open inter-organizational information system. Inter-organization information systems are undoubtedly the most prominent of the many cases of information technology used to gain a competitive advantage.

\section{Chinese Research Status}

\section{Chinese Volume Statistics}

This theme is filtered used the academic periodicals included in the CNKI database as a statistical source. The specific approach is to use the inter-organizational information system, inter-enterprise systems, cross-organizational information systems, information systems synergies as the keyword search. The export of the documentary records is used the SATI tool to do the text formatting. Then the literature records are derived into the database using contrast function to match exactly and exclude the duplicate operations. After the match finally 123 valid documents are left. In order to understand the research trend of inter-organization information system, the annual volume statistics are counted and the results shown in Figure 1. 


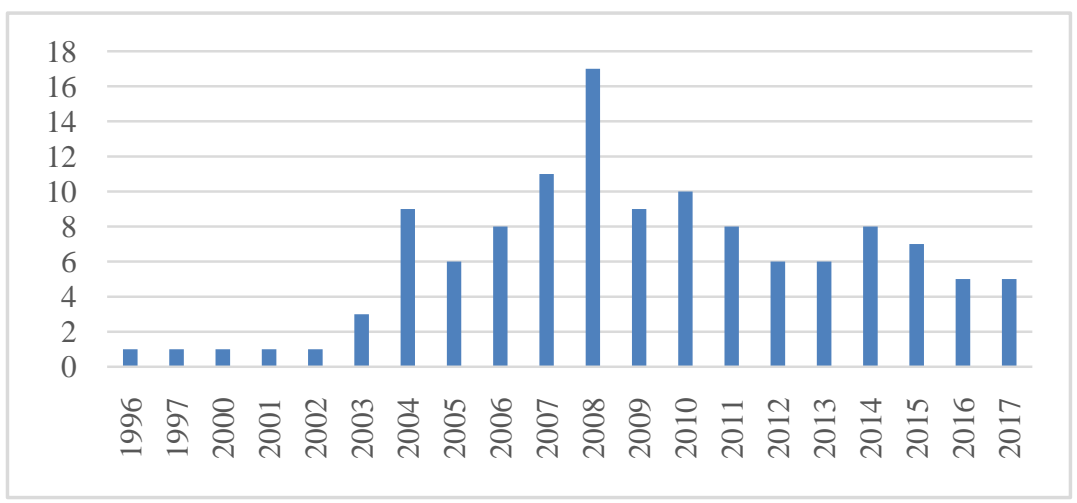

Fig.1 Annual statistics of relevant research on inter-organizational information system in China

According to the analysis of the literature on the trend of annual publication, Zheng Shigui[1] [1996] analyzed the advantages and prospects of the development of the international border information system by analyzing the global cash management system. Until 2003, Zheng Xin, Zhang Cheng and Ling Hong[2] from Fudan University introduced in order to realize information sharing among the members of the supply chain management system, the information platform based on the sharing of supply information is set up. Subsequently, the research of information systems across organizational boundaries is gradually enriched. By comparing the annual volume of literature found that 2008 is the key to the diffusion of inter-organizational information systems. It has become a hot topic that scholars began to study the environment, technology, organizational perspective to improve the inter-organization information systems[3]. At the same time, Chinese research on inter-organizational information systems has been gradually stabilized.

\section{Chinese Send Time Characteristics Analysis}

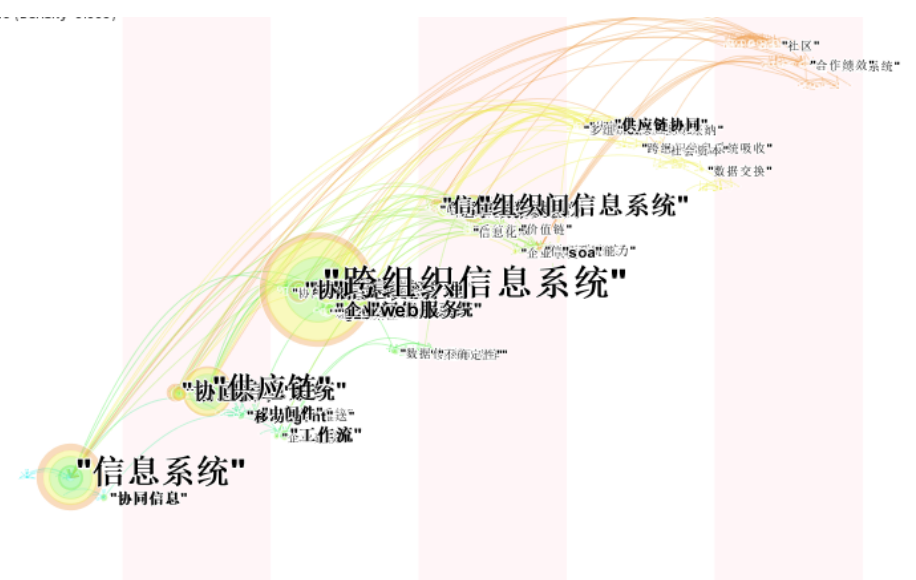

Fig 2. Inter-organization information system issued time series

In order to understand the key time change of the inter-organization information system research more clearly, the Citespace tool was used to convert the collected document records. Time-frequency distribution of key words was carried out by using timeline figure(setting time node as 5 and keyword node as 100\%). As shown in Figure 2, different colors indicate different years, from green to yellow in increasing order. As can be seen from the first time node in the figure, the collaborative information capability of an inter-organizational information system is the starting point for this study, in order to achieve the exchange of information between the coordination departments. The analysis of the high-frequency words of the second time node found that the supply chain management system in our country is an important area for the research of inter-organization information system. The incident handling and work-flow in the supply management process have been attracting much attention from scholars. Subsequently, some scholars applied the inter-organizational information system synergy ideas to enterprise resource 
management and the main application areas are for office automation research, improve enterprise resource utilization. At present, the research on inter-organizational information systems focuses on the application of community information systems and on the performance of inter-organization information systems.

\section{The Key Words Related to Domestic Research Co-Occurrence}

The SATI tool was used to extract 123 key words from the collected data, and statistical statistics were used to calculate the word frequency. The extracted keywords are imported into the database, and the similar keywords are searched and merged by using the wildcard [**]. Finally, the word frequency distribution table of diffusion key words of the inter-organization information system is obtained, as shown in Table 1 (word frequency> 6). After removing the search terms, we can find that the main purpose of the research on inter-organization information system in our country is to improve the information sharing ability. The type of information system is dominated by supply chain management system. In the study of inter-organization information system, information technology, organizational structure, industry system, sharing ability, transaction cost, leader ability, industry policy and other factors have gradually become the focus of research.

Table1. Key Words Frequency Distribution

\begin{tabular}{|l|l|l|l|}
\hline Key Words & $\begin{array}{l}\text { Word } \\
\text { Frequency }\end{array}$ & Key Words & $\begin{array}{l}\text { Word } \\
\text { Frequency }\end{array}$ \\
\hline $\begin{array}{l}\text { cross organization } \\
\text { information system }\end{array}$ & 52 & $\begin{array}{l}\text { performance capability of } \\
\text { information system }\end{array}$ & 18 \\
\hline $\begin{array}{l}\text { Information sharing } \\
\text { capability }\end{array}$ & 34 & $\begin{array}{l}\text { cooperative business } \\
\text { communication }\end{array}$ & 16 \\
\hline information technology & 32 & trust mechanism & 16 \\
\hline $\begin{array}{l}\text { supply chain } \\
\text { management }\end{array}$ & 27 & $\begin{array}{l}\text { information system } \\
\text { integration }\end{array}$ & 15 \\
\hline $\begin{array}{l}\text { Interorganizational } \\
\text { Information System }\end{array}$ & 26 & transaction cost & 15 \\
\hline $\begin{array}{l}\text { information technology } \\
\text { adoption }\end{array}$ & 23 & $\begin{array}{l}\text { leadership and management } \\
\text { ability }\end{array}$ & 12 \\
\hline $\begin{array}{l}\text { Interorganizational } \\
\text { Structure Relationship }\end{array}$ & 22 & $\begin{array}{l}\text { cross organizational } \\
\text { information system absorption }\end{array}$ & 10 \\
\hline $\begin{array}{l}\text { social capital and } \\
\text { background }\end{array}$ & 18 & $\begin{array}{l}\text { organization management } \\
\text { model }\end{array}$ & 8 \\
\hline $\begin{array}{l}\text { industry and enterprise } \\
\text { system theory }\end{array}$ & 18 & the support of industry policy & 6 \\
\hline
\end{tabular}

Converse the format of the merged keyword, and import citespace. Cluster the keywords extracted by using keyword co-occurrence and system clustering method. The results are shown in Figure 3. A total of 19 categories are obtained after the current treatment, and the closer the colors in the figure indicate the closer the categories are. Analysis of the contents of the class found that there was a crossover between some categories. To better understand the research association, some of the categories were merged according to the similarities of the contents. The results of clustering show that the current domestic research presents the following characteristics: supply chain coordination centered on supply chain management and information flow, inter-organizational information coordination research based on cloud computing technology, research on collaborative information system with the information structure at its core ; acceptance of information technology based on electronic data exchange technology; research on system integration with electronic commerce system as the core; research on enterprise information system coordination, web services and collaborative management with enterprise information resource management as the core; International information sharing as the core of the global information system research; 
organizational functions as the core on the information system restructuring, organizational structure of the internal research; research on information system with the capabilities of the organizational communication skills and leadership at its core.

Use time series to decompose different categories, as shown in Figure 4. According to the result of cluster analysis above, we can divide the inter-organization information system into three parts according to the starting point similarity: first part, supply chain management changes to the direction of system synergistic diffusion, second part, the data conversion technology of the e-commerce system changes the trust direction; Third part, Inter-organizational Information System diffusion from Inter-organizational Information System Integration to information system capability. In these three directions, the status of inter-organization information system has been continuously improved, and the value of inter-organization information and information system has been gradually realized.

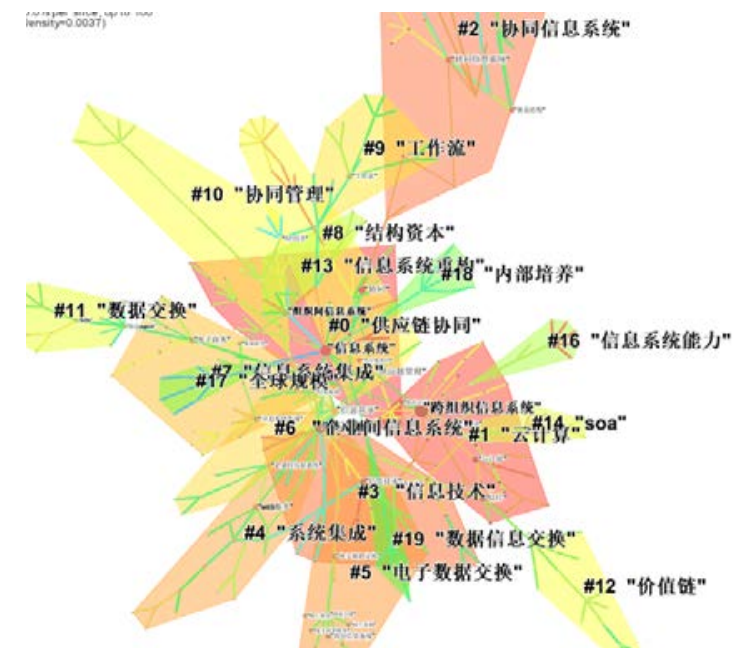

Fig 3. Key Words Clustering Analysis

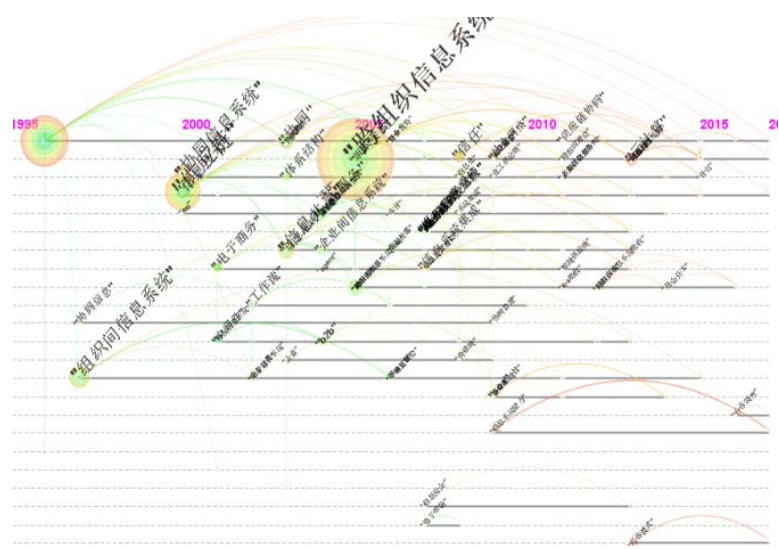

Fig 4. Keywords Clustering Time Series Map

\section{The Author of the Chinese Research Cooperation Analysis}

In order to establish the relationship among various factors in the inter-organizational information system diffusion model, we need to interview the relevant scholars in the inter-organizational information system research. Using the SATI tool to extract the authors and conducting frequency statistics, it was found that there were 190 authors who collected data this time. The highest volume was 4 , and the authors who published the volume 3-4 were 10 . In this article, we use Price's approach to identify core authors. In the same subject, half of the papers were written by a group of high-productivity authors whose number is approximately equal to the square root of the total number of authors. By comparing the number of authors with high productivity less than the square root of the total number of authors, we can see that no core circle has been formed in the field of inter-organization information system diffusion and the output of results is less.

Table 2. High Frequency Author Distribution

\begin{tabular}{|c|c|c|c|}
\hline Author & amount of writing & Author & amount of writing \\
\hline Mingming HE & 4 & Gang QU & 3 \\
\hline Jiang ZHU & 4 & Yongyi WU & 3 \\
\hline Xuan XIAO & 4 & Shuting ZHU & 3 \\
\hline Shu'e MEI & 3 & Jiao WANG & 3 \\
\hline Weijun ZHONG & 3 & Tienan WANG & 3 \\
\hline
\end{tabular}

In this statistical data, the cooperation rate is 1.54. To further understand the cooperative relationship among the inter-organizational information system research, we use the citespace tool to extract the authors' fields and present the author cooperation in a co-occurrence manner, as 
shown in Figure 5. It is found that there is a high degree of cooperation in the inter-organizational information system collaborative research in our country. Combined with the high frequency authors and authors in Table 2, Mingming He, Jiang Zhu and Xuan Xiao of Harbin Institute of Technology is found that they are high frequency authors. They mainly study the affection mechanism of social capital on the absorption of Inter Organizational Information System. In the article: the study of the influence mechanism of social capital on Inter Organizational Information System absorption [4], mentioned that the effective use of Inter Organizational Information System (IOS) has become a key element to improve business performance. It indicates that if the information system is accepted and effectively used by the organization which can effectively improve business performance. At the same time, the non-technical factors such as the inter-firm relationship and the corporate knowledge and behavior play an important role in coordinating the system and organizing the business processes and management processes when using the information systems. They also point out that social capital plays a decisive role in the application of inter-organizational information systems .

Southeast University Shuting Zhu, Weijun Zhong, Shu'eMei [5][6] mainly study the effect of the inter-firm information system value. In the article: research on the value creation of information system governance among enterprises, they used Chinese enterprises survey data derived that the communication between the IOS assets and enterprises does not directly affect the performance of enterprise cooperation, but rather the relevant conclusions of the enterprises on information system management through the intermediary process of inter-firm information system governance. Indicating that the application of inter-organizational information systems is part of business management and that management capabilities can influence the performance of inter-organizational information systems.

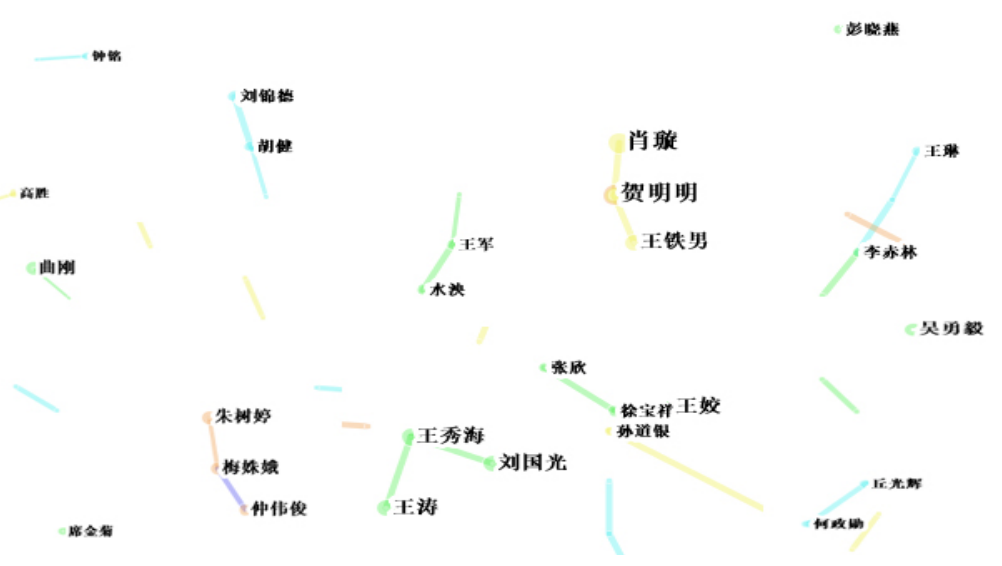

Fig 5.Authors' cooperative map of the relevant research on the inter-organizational information systems in china

\section{Foreign Research Status}

\section{Distribution of Foreign Literature}

Use the core collection included in the WOS database as a statistical source for topic selection. The specific method is to use IOIS as the keyword search, the export of the article records using SATI tools for format standardization, and export the data into the database to complete the data cleaning (using [*]\% to realize the standardization of word spelling rules, Using the GROUP function to sort cases). Respectively, the keyword, subject, author column is used SQL similarity query function to take the similar replacement. After matching we got a total of 178 valid documents, and the first we take the volume of annual statistics, as shown in Figure 6. 


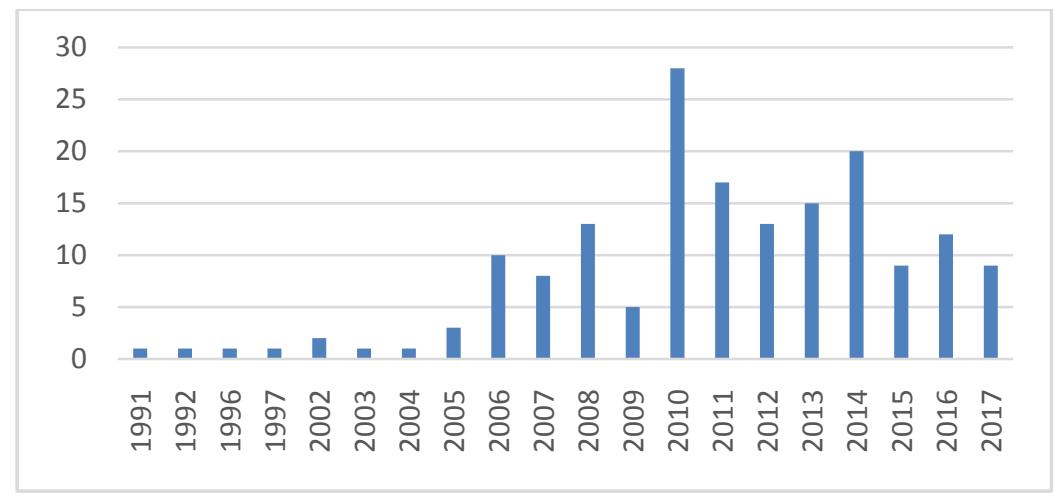

Fig 6. Foreign inter-organizational information systems related research papers volume statistics

In 1991 Michelman[7] explored the competitive strategy of inter-organization information system from the perspective of multivariate information system and explored the multivariate information system model of the pharmaceutical industry. Subsequently, the inter-organization information system entered a stage of steady development. Until 2006, Francis[8] and other scholars as the representative scholars optimized the inter-organizational relations by exploring the effect of the operation of the information system. The inter-organizational information system research come into the rapid development stage. By 2010, the research on user privacy risks, supply relationship management and corporate culture gradually entered into the eyes of researchers. Subsequently, the research content of the inter-organization information system has been continuously enriched and the results also tended to be steady.

\section{Foreign Research Keywords Co-occurrence}

Use Citespace to visualize the key words of foreign organizations in the diffusion of information systems, as shown in Figure 7 and Figure 8. In terms of keyword statistics, the number of cross-organization, inter-organizational systems, inter-organizational information system and information systems that occur the most. As can be seen in the figure, the number of supply chain systems, e-commerce systems, business process management systems, management control systems, e-commerce systems is also not a rare occurrence, which shows that most of the foreign research on the diffusion of inter-organizational information systems based on a single system or these systems as their empirical research case. Furthermore, the research on the diffusion of information systems among organizations in foreign countries mainly focuses on trust, structure, diffusion of innovation and industry level. These keywords appear not in a few and in Figure 9 we can find that these keywords are not clustering, which shows that the foreign research on the diffusion of inter-organizational information systems is relatively simple. Most of them are from a certain angle of research, and the establishment of the overall model is less.

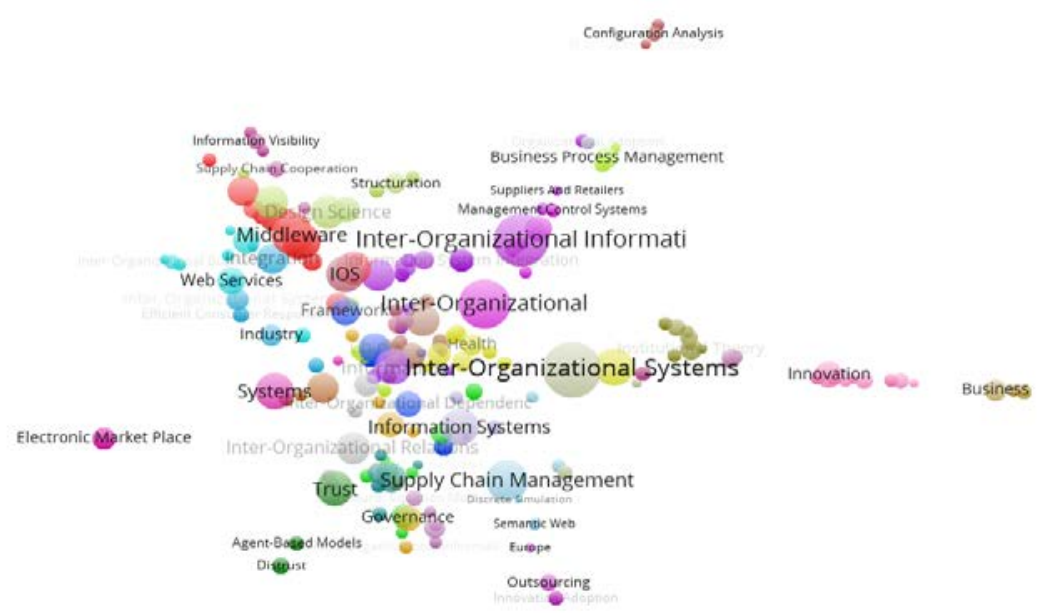

Fig7. Relative key words of interorganizational information systems 


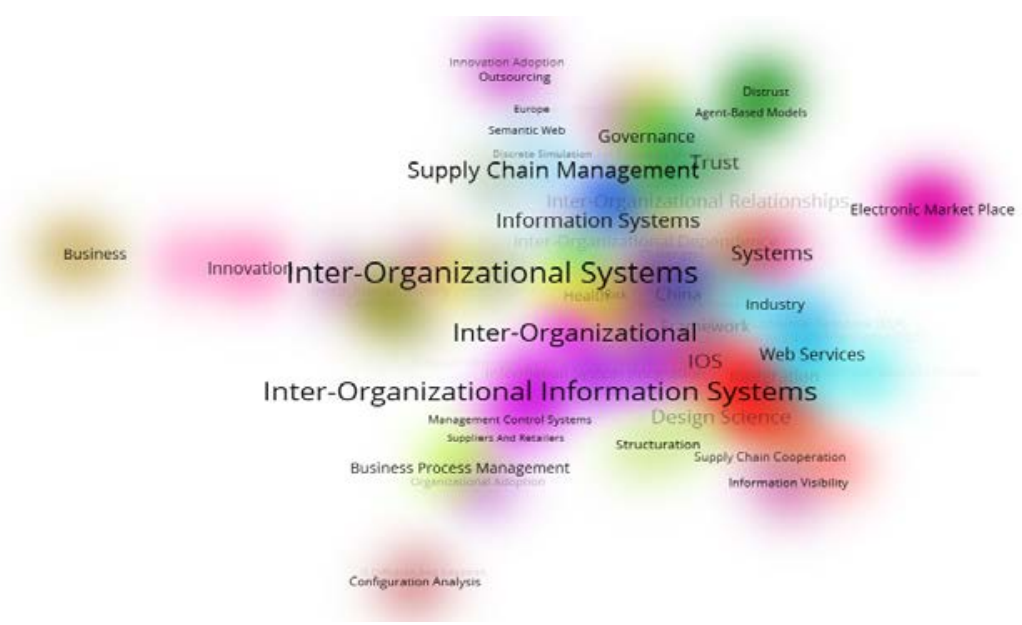

Fig 8. Foreign interorganizational information system related research keywords clustering

\section{Foreign Research High Frequency Author Analysis}

Statistical analysis of high-frequency authors, as shown in Table 2-3, shows that Reimers [9] has a deep research on the organizational relationship of multivariate systems in e-commerce and a certain life-cycle of inter-organizational information systems. Johnston[10], Center for Information Technology and Organization, University of Dublin, uses case studies to analyze the multi-level development of China's e-commerce system. In the collected data, the number of foreign scholars who published more than 3 documents accounted for a large proportion of high-frequency authors.

Table 2-3. Foreign High Frequency Authors Distribution

\begin{tabular}{|l|l|l|l|}
\hline Author & amount of writing & Author & amount of writing \\
\hline Reimers Kai & 6 & Sese Feliciano & 4 \\
\hline Rodon Juan & 4 & Choe Jong-min & 4 \\
\hline Li Mingzhi & 4 & Xie Bin & 3 \\
\hline Johnston Robert B. & 4 & Janssen M & 3 \\
\hline Klein Stefan & 4 & Guo Xunhua & 3 \\
\hline
\end{tabular}

\section{Foreign Studies Author Cooperation Analysis}

In order to further understand the distribution of core authors in inter-organization information system research, a pattern of co-occurrences is presented as shown in Figure 9. It is found that there is a clear cooperation in the field of inter-organizational information system collaborative research in foreign countries and the cooperation is concentrated. The diffusion of inter-organization information system research mainly from the industry level is represented by Li Mingzhi[11] of Tsinghua University. the case of Feliciano of University Ramon Llull[12] and others studied the diffusion of inter-organizational information systems based on the theory of social structure. Janssen[10] of Delft University of Technology mainly studied the establishment of inter-organization information system framework. 


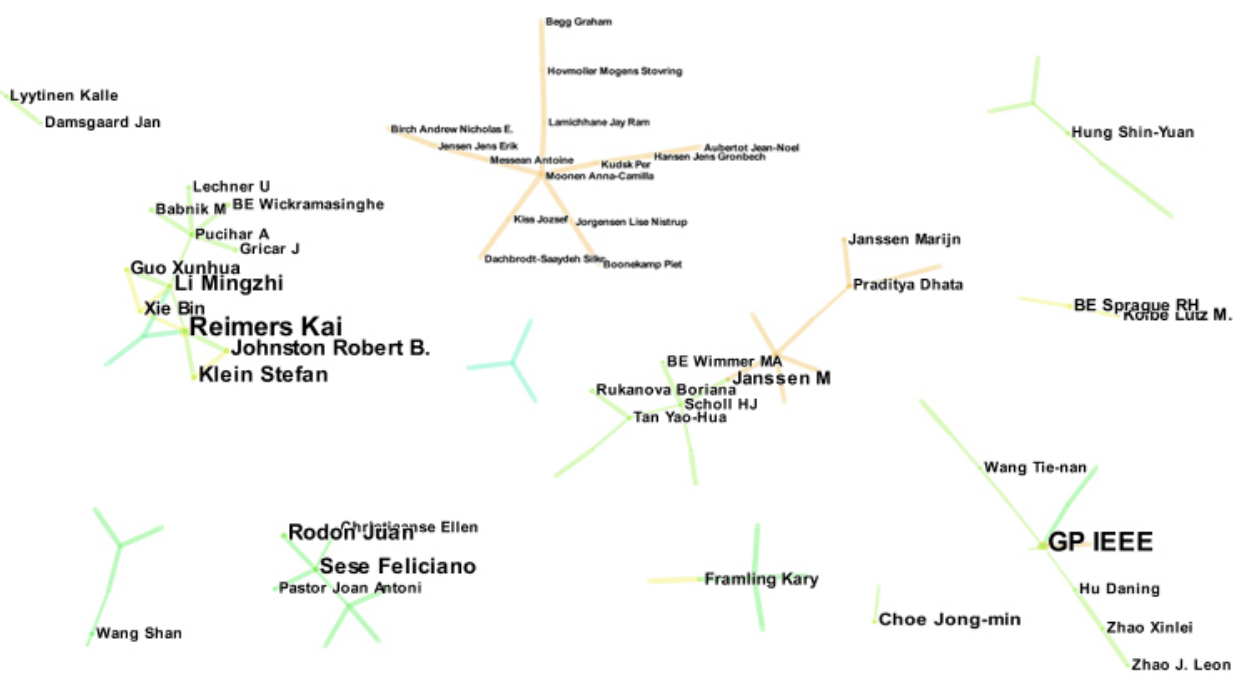

Fig 9. Analysis of foreign organizations cooperation related to interorganizational information systems

Reimers and Li Mingzhi[11] put forward a process of demonstrating the emergence of an industry-wide information infrastructure (IIIS) from both a corporate and industry level, and for the first time demonstrate that the emergence of IIIS and the industry life cycle of dispersed industries are complex connect together. And also explores the relationship between industry level and enterprise level life cycle in the process of emergence of IIIS. Finally, the survey results show that the current policy measures to promote the development of international monitoring system have not fully considered the industry-level conditions.

Feliciano[12] provides a non-adopted explanation, highlighting the potential structural changes brought about by the adoption of IOIS. Relying on the concepts of social structure, structural duality and structural contradiction of structural theory, he built a framework based on previous research into the diffusion of IOIS, including innovative characteristics, cognitive responses / beliefs, adopter characteristics and the environment feature. Based on existing factor models, organizational and individual aspects are used for analysis. And he believes adopters would think the system less useful when changes in configuration disrupt adopters' interests. According to the basic social structure of IOIS, he developed a taxonomic adoption of IOIS that focuses on resource rules and allocation in an inter-organizational context, and the configuration of the fabric can be changed by using IOIS. The significance of his research is that by anticipating the potential changes in the configuration of the structure resulting from IOIS adoption, management can anticipate the various conflicts that may appear on the horizon and adjust its strategy accordingly.

Janssen[10] then counted the inter-organizational system implementation literature and cites 27 factors affecting the spread of IOIS. He classifies these factors using the TOE framework, mainly from technical factors, organizational factors and environmental factors. He also used expert interviews to identify the most important factors that affect the spread of IOIS, including organizational readiness, management support and systems governance. During the interview, he found that organizational readiness plays an important role in the proliferation of IOIS. At the same time, interviewees also emphasized the interdependence of IOIS governance.

\section{Organization of Information Systems Research Review}

Through the use of bibliometric analysis of domestic and international inter-organizational information system collaborative research found that:

1) From the perspective of literature output, the diffusion of inter-organizational information system is low in our country. The annual output is low, and the output in the literature shows a downward trend, and gradually tends to be gentle in recent years. While in foreign countries, slightly higher than the domestic, but the trend is almost the same as the domestic. 
2) From the cooperation of the author, the situation of cooperation abroad is more obvious than that in China. Although the cooperation among domestic authors is relatively large, the network formed by them is smaller and far away, making it difficult to generate new cooperation. Foreign high-frequency authors are slightly better than domestic authors both in the number of authors and papers, and foreign authors have more cooperation networks than their domestic counterparts, and they are more likely to have new collaborations on the topics of the inter-organizational information systems research. For example, not only have Reimers collaborated with many foreign authors such as Johnston, but also collaborated more than once with authors such as Li Mingzhi at Tsinghua University. In the long run, this trend of cooperation in our country will not be improved.

3) From the point of view of research content, researches on inter-organizational information systems are very similar both at home and abroad, with more studies on individual factors and less on the whole model. For example, He Ming Ming[2]studied the absorption of Inter Organizational Information System from the perspective of social capital. While Chen Wenbo[13] and others from the perspective of trust and coercive power to study the inter-organizational information system diffusion. Feliciano[12] from the perspective of social structure to study the diffusion of inter-organizational information systems. Although Janssen[10] counted a large number of factors that contributed to the proliferation of information systems among organizations, it did not build a holistic model, but only explored a question of what factors have a deeper impact. From the current research on the diffusion of inter-organizational information system, there is a lack of model research on the factors influencing the diffusion of inter-organizational information systems. Although there are many influential factors, they are scattered and the study on the relationship between influential factors is less.

\section{Conclusion}

Although there is no obvious increase in the research on inter-organization information system, its research value still exists, and it has great research value. The influencing factors of dispersion make the influence factors of inter-organizational information system more complicated. Building a relatively complete model of influencing factors is an urgent problem to be solved in the diffusion of information systems among organizations.

\section{Acknowledgement}

This research was financially supported by the National Social Science Foundation of China (No. 13CTQ041).

\section{References}

[1]Zheng Shigui. Global Cash Management System Evaluation [J]. Management Science Abstracts, 1996 (08): 45.(in Chinese)

[2]Zheng Xin, Zhang Cheng, Ling Hong. Evaluation of the sharing of supply information in supply chain management value [J]. Chinese Journal of Management Science, 2003 (03): 24-30. (in Chinese)

[3]Chu Chu, Zhang Song. Inter-organizational information system diffusion factors [J]. (in Chinese)

[4]Journal of Management Science, 2014,17 (05): 66-83. [4] He Mingming, Wang Tienan, Xiao Xuan. Research on the Impact Mechanism of Social Capital on the Absorption of Cross-organizational Information System [J] (in Chinese)

[5]Zhong Weijun, Tao Qing, Mei Shu'e.Study on the Strategic Planning of E-business among Enterprises [J]. Chinese Journal of Management, 2002 (02): 22-28. (in Chinese)

[6]Mei Shu E, Zhong Weijun.On the inter-organizational information system [J]. Management 
Information System, 1997 (12): 6-9. (in Chinese)

[7]Schwartz RM, Michelman T, Pezzullo J, et al. Explaining resource consumption among non-normal neonates [J]. Health Care Financing Review, 1991, 13 (2): 19-28.

[8]Iriana R, Volume F B, Number. Customer Relationship Management (CRM) System Implementations [J]. Organization Collection, 2006, 216 (2): 137-148.

[9]Kai R, Johnston R B, Klein S. An empirical evaluation of existing IS change theories for the case of IOIS evolution [J]. European Journal of Information Systems, 2014, 23 (4): 373-399.

[10]Rahim M M, Shanks G, Johnston R B. A cross industry comparison of inter-organization systems implementation activities [J]. Electronic Commerce Research, 2011, 11 (2): 215-243.

[11]Kai R, Li M, Xie B, et al. How do industry-wide information infrastructures emerge? A life cycle approach [J]. Information Systems Journal, 2014, 24 (5): 375-424.

[12]Rodón J, Sesé F. Analysing IOIS adoption through structural contradictions [J]. European Journal of Information Systems, 2010, 19 (6): 637-648.

[13]CHEN Wen-Bo, ZHANG Lu, LIU Jian-Lin.Effects of Interorganization Trust and Coercive Power on the Application of Inter-organizational Information System [J]. Soft Science, 2015,29 (08): 107-110. (in Chinese)

[14]He Mingming. Research on the Value Creation of Cross-organizational Information System Based on Absorption Perspective [J] .Journal of Jiangsu Science and Technology Information, 2017 (33): 29-33. (in Chinese)

[15]Wang Li. Synergistic development among independent organizations multi-stage collaborative behavioral research [D]. Dongbei University of Finance and Economics, 2016. (in Chinese)

[16]Jun-Shan Zhang. Cross-organizational information systems, knowledge innovation and the relationship between the role of value [D]. Hebei University of Technology, 2015. (in Chinese)

[17]Song Yingjie. Empirical research and implementation of cloud-based trust mechanism of cross-organizational information system [J] .Journal of Heilongjiang Eco-Engineering Vocational College, 2014,27 (04): 45-46. (in Chinese)

[18]Zhu Jiang, Lai Jiawei. A Review of Research on Trust in Cross-Organizational Information Systems Based on Cloud Computing [J] .Science and Technology Management Research, 2014,34 (11): 192-196. (in Chinese)

[19]ZHU Jiang, TONG De-rong, LAI Jia-wei.An empirical study of cloud-based trust mechanism of cross-organizational information system [J] .Application Research of Computers, 2014,31 (10): 2947-2951.

[20]He Mingming, Wang Tienan, Xiao Xuan. An Empirical Study on the Impact of Structural Capital on the Inter-organizational Information System [J] .Journal of Harbin Engineering University, 2012,33 (07): 916-922. (in Chinese)

[21]Zhou Aihua. Supplier - retailers cross-organizational information system to adopt the impact of factors [D]. Harbin Institute of Technology, 2011. (in Chinese)

[22] ZHANG Jun, TANG Bai-hong, LI Yang. Research on the Reconfiguration Model and Supporting Technology of Information System Between Organizations [J]. Journal of Hunan University of Commerce, 2011,18 (02): 33-37. (in Chinese)

[23]LV Hui, YE Fei, QIANG Rui.Effects of Supply Chain Resource Dependence, Trust and Relationship Commitment on Information Collaboration [J]. Industrial Engineering and Management, 2010,15 (06): 7-15. (in Chinese) 
[24]XIAO Xuan. Research on the influencing factors of automobile industry cross-organizational information system adoption in compulsory environment [D]. Harbin Institute of Technology, 2010. (in Chinese)

[25]Chu Rui. An empirical study of the influencing factors of cross-organizational information system diffusion [D]. Qingdao University, 2010. (in Chinese)

[26] CHEN Wen-Bo, ZENG Qing-Feng, HUANG Rong-Hui.Research on the Interactive Relationship between Cross-organizational Information System and Social Networks [J] Journal of Soft Science, 2010,24 (01): 42-45 + 55. (in Chinese)

[27]XU Meng-dan, LI Xing-hua, ZHAO Shu-jin.Research progress on inter-organizational information system in supply chain [J] .Science and Technology Progress and Policy, 2008 (05): 196-200. (in Chinese)

[28]Liu Fengxia, Chang Dalei. Acquisition and maintenance of cross-organizational information system and competitive advantage [J] .Science \& Technology Progress and Policy, 2007 (01): 127-130. (in Chinese)

[29]Tao Zhiying, Hu He-ning. The important role of organizational communication in establishing successful inter-organizational information system [J]. The Media, 2007 (01): 58-59. (in Chinese)

[30]Wang Ying, Wang Fanghua. Organizational Structure Effect of Cross-organizational Information System [J] .Journal of Intelligence, 2006 (02): 46-48 + 51. (in Chinese)

[31]Qin Li. An interdisciplinary information system theory from the perspective of organizational relations [J]. Mall Modernization, 2006 (02): 30-32. (in Chinese)

[32] Zhao Zhiyun.Technical framework and application analysis of cross-organizational information system [J]. Inner Mongolia University of Finance and Economics, 2005 (03): 66-68. (in Chinese)

[33]Yan Jian-aid, Xu Bin. The Impact of Inter-organizational Information System on the Relationship among Cooperative Organizations [J]. Soft Science in China, 2005 (03): 117-125. (in Chinese)

[34]Rajaguru R, Matanda M J. Effects of inter-organizational compatibility on supply chain capabilities: Exploring the mediating role of inter-organizational information systems (IOIS) integration [J]. Industrial Marketing Management, 2013, 42 (4) 620-632.

[35]Sigala M. Examining the adoption of destination management systems [J]. Management Decision, 2013, 51 (5): 1011-1036.

[36]Lyytinen K, Damsgaard J. Inter-organizational information systems adoption - a configuration analysis approach [J]. European Journal of Information Systems, 2011, 20 (5): 496-509.

[37]Kreuzer S. Explaining organizational susceptibility to coercive pressure: results from a field experiment on e-invoicing IOIS adoption [J]. Information Systems and e-Business Management, 2016, 15 (1): 1-37.

[38]Lyytinen K, Damsgaard J. Configuration Analysis of Inter-Organizational Information Systems Adoption [J]. Lecture Notes in Business Information Processing, 2010, 60 (16): 127-138.

[39]Chaparro-Peláez J, Pereira-Rama A, Pascual-Miguel F J. Inter-organizational information systems adoption for service innovation in building sector [J]. Journal of Business Research, 2014, 67 (5): 673-679 .

[40]Saglietto L, Pigni F. Interorganizational Information Systems Diffusion: A Social Network Perspective [C] // International Conference on Information Intelligence, Systems, Technology and Management. Springer Berlin Heidelberg, 2011: 350-354. 